REVISTA ANDALUZA DE ANTROPOLOGÍA.

NÚMERO 11: TRABAJO Y CULTURAS DEL TRABAJO EN LA GLOBALIDAD HEGEMÓNICA

SEPTIEMBRE DE 2016

ISSN 174-6796

[pp. 92-120]

http://dx.doi.org/10.12795/RAA.2016.11.05

Recibido: 17/05/2016

Aceptado: 12/07/2016

\title{
DE SUR A NORTE, DE NORTE A SUR: EL BALANCE LABORAL DE MUJERES CUALIFICADAS MIGRANTES POR AMOR
}

\section{FROM SOUTH TO NORTH, FROM NORTH TO SOUTH: THE WORK BALANCE OF QUALIFIED LOVE-MIGRANT WOMEN}

Jordi Roca Girona

Universidad Rovira i Virgili

\section{Resumen.}

Este artículo se centra en la realidad laboral de un grupo de mujeres con formación universitaria y que forman parte de una pareja binacional heterosexual, en su migración por amor desde el "norte global" hacia el "sur global", o viceversa. La investigación muestra el impacto negativo en las carreras profesionales y un crecimiento de la carga de trabajo doméstico para estas mujeres. En cuanto al empleo, las consecuencias se centran en el descenso de la movilidad ocupacional, la disminución de ingresos, la mengua de la perspectiva de desarrollo profesional, la reorientación de la carrera y la aparición del subempleo o el desempleo. En lo referente a la vida familiar, el impacto se mueve en un rango que va desde el aumento de las responsabilidades de la casa y/o el cuidado de los hijos a la completa inmersión en la esfera doméstica. En definitiva, aquello que se constata en los términos más extremos, es un proceso de transformación de una 
profesional cualificada en un ama de casa, y de una mujer autónoma financieramente a una dependiente de su marido.

Palabras Claves: Migración cualificada, migración femenina, parejas binacionales, migración matrimonial, roles de género.

\section{Abstract.}

This article focuses on the work trajectories of a group of highly qualified women, members of heterosexual binational couples, on their love migration from the "global north" to the "global south", or vice versa. Research shows a negative impact on their careers and a growing domestic workload. Regarding to the employment, we find a decreasing occupational mobility, lower incomes and lesser professional perspectives, career reorientations and the apparition of underemployment or unemployment. Concerning to their family life, the effect ranges from increased household and / or childcare responsibilities to a full immersion into the domestic sphere. The most extreme scenario shows a process of transformation from a highly qualified professional to a housewife and from a financially autonomous woman to one dependent on her husband.

Keywords: Highly skilled migration - women migration - binational couples - marriage migration - gender roles.

\section{1.- DE LA MIGRACIÓN DESESPERADA A LA MIGRACIÓN ESPERANZADA: UNA PANORÁMICA DEL DESARROLLO DE LA LITERATURA SOBRE MIGRACIONES}

En general, la literatura clásica sobre migraciones daba por hecho la causalidad económicolaboral de estos movimientos poblacionales (véase, por ejemplo, Harris y Todaro, 1970), así como su carácter individual y mayoritariamente masculino. Posteriormente apareció un enfoque fundamentado en la teoría de la dependencia, menos individualista que la "migration theory" (Rothenberg, 1977) y centrado en las desigualdades inherentes al sistema capitalista global y en la división internacional del trabajo, que explicaría las relaciones de dependencia de los países "periféricos” respecto a los llamados países centrales (Zolberg, 1983) y la utilización de los trabajadores extranjeros como "ejército de reserva". Este tipo de planteamientos marcaron fuertemente la manera de conceptuar, teorizar y pensar la migración, y contribuyeron a inferir, implícitamente, que todos los migrantes son socialmente inferiores -pobres, incultos, analfabetos, marginales, desesperados, etc. - a los miembros de las sociedades de acogida.

Las mujeres, percibidas tradicionalmente como ajenas a la esfera pública y al mercado laboral, aparecían invisibilizadas o pasivas en los procesos migratorios, aunque este 
paradigma empezó a cambiar poco a poco. Así, en el último cuarto del siglo pasado comenzó a hablarse de migraciones multicausales, entre las que se incluyeron las propiciadas por motivaciones políticas, las de trabajadores cualificados, las de jubilados, etc. Igualmente, los organismos internacionales pusieron el foco en el número creciente de migraciones femeninas. El género empezó a ser utilizado como categoría de análisis en esta temática ante el incremento cuantitativo de mujeres en los flujos migratorios, la elevada tasa de actividad económica de las mujeres inmigrantes en las sociedades de destino y el debate feminista en torno a la posición de la mujer en la sociedad y las relaciones de género. En este contexto, diversas investigaciones comenzaron a compensar la invisibilidad previa de las mujeres migrantes (Phizacklea, 1983; Morokvasik, 1984; Knörr y Meier, 2000; Anthias, 2000; Hondagneu-Sotelo, 2001; Parreñas, 2001; Ehrenreich y Hochschild, 2003 entre otras). Pero debido a la división sexual y étnica del trabajo a escala internacional y de la presencia de diversas formas de segregación sexuada, la mayoría de las investigaciones sobre mujeres inmigrantes seguía ocupándose de determinados sectores de actividad a las que ellas parecían estar confinadas (servicio doméstico y de cuidado, prostitución, trata...), todas actividades socialmente desvalorizadas y poco cualificadas (Catarino y Morokvasic, 2005). Además, los estudios siguieron centrando su atención primordialmente en el ámbito económico-laboral, sin incorporar las nuevas geografías y tipologías migracionales (King, 2002), entre las que se hallarían las que nosotros hemos denominado "migraciones por amor" (Roca, 2007), protagonizadas por personas que emprenden la aventura migratoria para formar una familia o una pareja binacional en destino. La sensibilidad por la variable de género y la perspectiva feminista en migración contribuyeron a generar nuevas aportaciones y a subrayar los incentivos no económicos de la migración (Harzing, 2001).

Penny y Khoo (1996: 29) señalaron hace ya dos décadas que el amor es uno de los motivos fundamentales para la migración. En la década de los noventa del siglo pasado empieza a notarse una presencia cada vez mayor de matrimonios mixtos en el marco de las que se han denominado "rutas globales de búsqueda de cónyuge" y, de manera simultánea, empiezan a proliferar las agencias especializadas en Internet (Constable, 2003).

D. Massey (1994), en el marco de su "geometría del poder", propuso explicaciones a por qué son usualmente las mujeres quienes se desplazan por razones de matrimonio, vinculándolo a la movilidad y el parentesco, que serían controlados por los hombres. Esta explicación enlazaría con la teoría de que históricamente las mujeres han sido objeto de intercambio en el mercado matrimonial y, por tanto, sujetos de movilidad por razones matrimoniales (Lévi-Strauss, 1981; Fox, 1967). Por su parte, Piper y Roces (2003: 11) sostienen que las mujeres serían presionadas socialmente desde todos los frentes para casarse como única forma de supervivencia, ya que su posición en el mercado laboral sería siempre más precaria que la de los hombres. 
Como ha señalado N. Constable (2005: 16), si bien los hombres cruzan las fronteras para encontrar esposas, habitualmente son las mujeres quienes las cruzan de manera más permanente, siendo relativamente pocos los hombres que tienen la opción de devenir migrantes matrimoniales.

Todas estas aportaciones se refieren, no obstante, única o principalmente a mujeres del "sur global" que emigran a países del "norte global" (Glodava y Onizuka, 1994; Halualani, 1995; Robinson, 1996; Ordóñez, 1997; Larsen, 1998; Scholes, 1999; Simons, 1999; Mainardi, 2006; Riaño y Baghdadi, 2007, entre otros). Además de las causas y factores que conectan el crecimiento de la migración matrimonial, especialmente de mujeres, con el aumento de los flujos migratorios globales, nosotros consideramos otras variables. Así, creemos que existe una relación directa con la ampliación del mercado matrimonial en la modernidad (Illouz, 2012: 75-78), con la emergencia y popularidad de las nuevas tecnologías de la información y la comunicación -TIC- (Roca, Anzil y Martínez, 2015) y con el paso de una sociedad centrada en la producción a otra centrada en el consumo y en la elección (Roca, 2011). Todos estos factores permiten la incorporación de las migraciones femeninas matrimoniales del "norte global" al "sur global", que han resultado prácticamente invisibles a la investigación y que van a constituir una parte de lo que vamos a acometer en este trabajo ${ }^{1}$.

No existe una definición unívoca internacionalmente consensuada de lo que se entiende por "profesional cualificado". En el Manual de Canberra de 1995 -el mayor acuerdo internacional alcanzado sobre el tema- un "profesional cualificado" es "aquel que haya adquirido un conocimiento que le habilite para trabajar en la generación, el avance, la difusión y la aplicación del conocimiento científico y técnico a través de la formación académica o de la experiencia ganada en el trabajo" (Citado por Díaz Gil, 2012: 7). Las regulaciones nacionales suelen optar por una definición que combina formación reglada y experiencia profesional para definir a su personal cualificado (Díaz Gil, 2012: 7).

Por otro lado, se observa una escasa atención a las experiencias de transformación de género de las mujeres migrantes cualificadas, en contraste con aquella prestada a las mujeres poco cualificadas y racializadas. Igualmente, la escasa literatura existente (Aure, 2013: 276), se fija en las profesionales demandadas, sobre todo en el ámbito de la salud y la educación, por los países del norte.

Para algunos autores la invisibilidad de las mujeres y las relaciones de género en los estudios sobre migración internacional cualificada es debida al énfasis puesto en las élites corporativas transnacionales, absolutamente masculinizadas (Kofman, 2000, Koser y

1. Los pocos trabajos que conocemos en este sentido se centran en matrimonios de mujeres del "norte global" con hombres del "sur global" pero residentes en países del norte (véase por ejemplo Joshi y Krishna, 1998), o bien en aspectos no relacionados directamente con el ámbito laboral (véase por ejemplo Roer-Strier y Ezra, 2006). 
Salt, 1997), en los que las mujeres aparecen generalmente como "esposas dependientes", al margen de su cualificación (Purkayastha, 2005: 182; Riaño y Baghdadi, 2007: 165). La literatura más específica sobre mujeres migrantes cualificadas y su trayectoria laboral -nuevamente, no obstante, de sur a norte- subraya el impacto negativo del proceso migratorio en las carreras de estas mujeres, describiéndose el proceso que sufren (des-cualificación, feminización y reorientación doméstica), intensificando el trabajo doméstico y reduciendo su actividad laboral a jornada de tiempo parcial (Meares, 2010: 473). La situación en destino de muchas de estas mujeres puede definirse como de subempleo, subocupación o de desempleo, y mal pagado (Man, 2004: 142; Cooke, 2007). La investigación centrada en este colectivo de mujeres es generalmente de tipo cuantitativo y se ha llevado a cabo predominantemente en aquellos países que han destacado por poner mucho énfasis en la cualificación como criterio para la selección de inmigrantes, como por ejemplo Canadá (Man, 2004), Europa (Dumont et al 2007) y Australia (Ho y Alcorso 2004). Algunos de estos trabajos muestran que cuando es la mujer cualificada quien sigue al marido cualificado en el proceso migratorio, el aumento del peso de la domesticidad en su vida es notorio y evidente, mientras que cuando sucede al revés, el trabajo doméstico no es asumido por el marido, sino que se delega en la contratación de servicio doméstico (Yeoh y Willis, 2005) ${ }^{2}$. Es diferente cuando la mujer emigra sola, dejando al marido y la familia en origen.

Nuestra aportación se centra en un colectivo escasamente estudiado: el de las mujeres migrantes cualificadas casadas binacionalmente. En nuestra muestra incorporamos tanto a mujeres del "sur global" migrantes por amor al "norte global" (más precisamente, a España), como mujeres del "norte global" (más exactamente españolas) que han migrado por amor al "sur global". También incorporamos los testimonios de algunas mujeres que llevaron a cabo una doble migración: del "sur global" al "norte global" y vuelta al sur, o viceversa. El foco de atención principal lo situaremos en las repercusiones laborales que este proceso migratorio tiene sobre este colectivo específico. Nos proponemos abordar un colectivo de mujeres altamente cualificadas, pero cuya migración no se realiza en el seno de una pareja o familia preexistentes, sino que es consecuencia del encuentro de un marido o pareja de otra nacionalidad ${ }^{3}$. Se trata de una aportación pionera puesto que no hemos hallado en la literatura sobre el tema ninguna referencia que aborde este colectivo,

2. Es evidente que hay que tener en cuenta la fase del ciclo vital en que se produce la emigración. Cuando la pareja es joven y no hay hijos la situación puede diferir bastante de la planteada, que es más propia de parejas que emigran con hijos o que los han tenido en destino. En este sentido, bien podríamos plantear que en algunos casos esta reorientación doméstica de las mujeres también hubiera podido producirse igualmente sin que mediara la migración, aunque posiblemente de forma algo más atenuada.

3. Curiosamente, en nuestra muestra, los hombres emparejados con mujeres migrantes del "sur global" acostumbran a no ser altamente cualificados, mientras que aquellos unidos a mujeres de "norte global" son tan o más cualificados que ellas. Véase el cuadro que recoge las características de las mujeres consideradas y de sus parejas masculinas. 
a excepción de alguna mención esporádica en el seno de artículos más generales (Aure, 2013).

\section{2.- UNA NOTA METODOLÓGICA}

Los datos de este artículo proceden de diversos proyectos de $\mathrm{I}+\mathrm{D}$ que venimos desarrollando desde 20064. Para este trabajo he seleccionado un total de 14 mujeres (véase el cuadro anexo) del conjunto de las más de 100 mujeres entrevistadas. Todas ellas poseen formación superior universitaria en campos distintos del conocimiento y desarrollan o han desarrollado una ocupación o profesión acorde a ella: abogacía, filología, traducción, consultoría, investigación social, ingeniería eléctrica, economía, arquitectura, banca, profesora, editora, comadrona, bailarina, dirección y administración de empresas, educadora y profesora de universidad ${ }^{5}$. Su edad oscila entre los 30 y los 48 años, siendo la media de 37,5 años. De ellas seis son españolas que emigraron, para casarse o ya casadas, a países extranjeros, donde viven actualmente: tres en Brasil, dos en México y una en República Centroafricana. Otras seis mujeres procedentes de México, Cuba, Venezuela, Perú, China y Japón migraron a España para casarse con un español. Las dos restantes son una mexicana que migró a España para casarse con un español y una española que conoció a un mexicano en España con quien se casó y emigró a México DF. Ambas habían regresado a sus países de origen con sus parejas e hijos en el momento de la entrevista. Los años de convivencia con la pareja de las mujeres entrevistadas oscilan entre los cuatro meses y los 20 años, siendo la media de 6,4 años. Del total de la muestra, cimco mujeres no tenían hijos, y de las nueve restantes, cinco tenían un hijo, tres tenían dos y una tenía cuatro. Por lo que a la formación de sus esposos se refiere, todas las mujeres españolas están casadas con hombres con titulación superior, mientras que de los siete hombres españoles casados con las mujeres extranjeras de la muestra solo uno tiene estudios universitarios, y el resto tienen estudios secundarios (4) o primarios (2).

Todas las mujeres de la muestra fueron entrevistadas en una o varias sesiones mediante la técnica de la entrevista guiada en profundidad. Siete de ellas fueron entrevistadas en España, principalmente en Tarragona y Barcelona, tres en México, tres en Brasil y una por Skype.

4. Hasta la fecha hemos llevado a cabo, entre otros, tres proyectos de investigación del Plan Nacional de I+D+I: 'Amor importado, migrantes por amor: la constitución de parejas entre españoles y mujeres de América Latina y de Europa del Este en el marco de la transformación actual del sistema de género en España', Min. de Trabajo y Asuntos Sociales (47/05): 2006-2008; 'Amores transnacionales: constitución y desarrollo de parejas mixtas en España', Min. de Ciencia e Innovación (CSO2009-10187): 2010-2012; 'Parejas mixtas residentes fuera de España: relaciones de género, dinámicas sociales y conexiones transnacionales', Min. de Economía y Competitividad (CSO2012-33565): 2013-2015.

5. Algunas de nuestras informantes desarrollan la misma profesión y/o tienen la misma titulación o tienen más de una titulación y han desempeñado más de una profesión. 


\section{3.- IRSE (POR AMOR)}

Vamos a presentar en este apartado a nuestras protagonistas, centrándonos en su situación laboral anterior a la emigración y en cómo influyeron en su decisión de migrar por amor las consideraciones de carácter laboral. Veremos en un primer momento a aquellas que realizaron la emigración a España desde distintos países, en segundo lugar a las que la realizaron desde España a otros países y, finalmente, a dos de nuestras protagonistas que han protagonizado una doble migración: de México hacia España y de nuevo hacia su país de origen en un caso y de España hacia México y de nuevo hacia España en el otro.

\section{1.- Destino: España}

-Akane (Japón, 30) conoció a Miquel (España, 26), su marido, en una estancia de trabajo de él en un parque temático de Japón donde ella trabajaba. Durante el tiempo que estuvieron juntos en Japón iniciaron una relación, que pensaban que acabaría cuando él volviera a España. En un viaje de visita de su madre al país nipón, esta le dijo a su hijo: "Si te dejas perder a esta chica, vas a ser muy, muy tonto y te vas a arrepentir toda la vida". Para Miquel este fue el detonante para pedirle que se viniera con él a España. Akane no lo dudó, y tras negociar quedarse un año más en Japón antes de venir a España “...para acabar de trabajar, porque tenía contrato y no puedes quedar mal en el trabajo, por... en parte por su manera de ser, y porque quería acabar de recoger un poco de dinero y hacerlo entender a su familia, y todo esto", decidieron casarse y empezar su vida en común en un pequeño pueblo del interior de Tarragona, viviendo en la casa de la madre de Miquel.

-Xuelin (China, 36) conoció a su actual marido (España, 39) en un chat. Cuando se conocieron ella estudiaba y trabajaba, y tenía claro que quería quedarse en China después de casarse. Pero según ella, en China era más difícil que él encontrara trabajo, por lo que decidieron venir a vivir a España.

-Sonia (Perú, 35), licenciada en Educación, trabajaba para el estado peruano como capacitadora social en zonas rurales cuando conoció a Javi (España, 37) en un chat: "Yo estaba soltera y le conocí a él, y nos gustaban las mismas cosas, pero... cómo lo hacemos trabajando yo allá. ¡Ay, me costó!". Después de un noviazgo de pocos meses, sin haberse visto nunca de forma presencial, deciden casarse. Después de la boda, ella se queda unos meses en Perú antes de venir a España:

"En ese momento estaba ilusionada, no pensaba, estaba como en las nubes o una cosa así. Y entonces cuando se va... digo: '¿qué hago?' Me puse de una manera, digo, 'mis amistades, mis padres...' Pero yo después veía a mi mamá... era lo que a mí me mataba. Pero de ahí digo: 'es mi vida, mi ilusión', digo, 'qué le voy a hacer, ya está la decisión tomada, yo no puedo hacer nada, porque ya estoy casada, no puedo estar en tonterías".

6. Entre paréntesis, después del nombre, señalamos el país de origen y la edad. 
-Sol (Venezuela, 37), conoció a Jordi (España, 41) en Venezuela:

"Yo era una chica normal. Me consideraba una chica muy afortunada por estar allá, porque realmente nosotros no hemos pasado necesidades. La idea que la gente tiene de que uno sale de este país por motivos económicos se aplica a otro tipo de personas, pero en mi caso no es así. (...) Mis padres decían lo típico, que tienes que estudiar, hacerte un futuro, sacarte una carrera, formar una familia... Bueno, y vivía con mis padres y... mis aspiraciones eran esas, terminar de estudiar y ejercer la carrera. (...) Bien, nos conocimos en el transcurso de esos días y en el transcurso de esos días también se habló de que bueno, que cuánto tiempo iba a esperar para que nosotros estuviéramos juntos... La única condición que le puse era que se esperara porque yo ya estaba a punto de salir de la universidad y me faltaba un año. Terminando la carrera le prometí que yo me mudaba con él y así fue. (...) también me pregunté si estaba haciendo bien de estar con esa persona, de que me tenga que ir. Pero al final sí, sí... se portó tan bien conmigo. (...) Él me mandaba dinero y tenía para el alquiler, para la comida, para todo... Y gracias a ellos dos [su madre y Jordi] terminé rápido la carrera. Y terminé en mayo, y en junio ya me vine para acá. Vendí todo lo que tenía, entregué el piso y me vine, el 21 de junio."

- Chivis (México, 30) terminó su licenciatura en Informática y tuvo una serie de trabajos informales hasta que "se me presentó la oportunidad y empecé a trabajar en un banco durante siete años". Pero conoce a Alejandro (España, 39), su marido, en un viaje turístico a Cuba. Al acabar las vacaciones y regresar a México:

"Empecé a llorar... y fue cuando me planteé: ¿sigo con esto o lo detengo? Fue muy doloroso, me sentía sola, me gustaba estar con Alejandro y me dije: 'bueno, vamos a ver'. Lo que me trajo aquí fue no pensarlo demasiado. Alejandro ha sido un no pensar".

Enamoramiento al margen, Chivis se plantea también la cuestión laboral:

"Yo veía la diferencia del trabajo de allí y el de aquí: yo, en México, podía salir a las siete de la mañana y regresar a las siete de la noche o más, mientras que aquí, él salía a trabajar en la mañana, regresaba a comer a mediodía y a las seis de la tarde ya estaba en casa".

Chivis no sólo valoró la afectación sobre su trabajo de la decisión de emigrar a España, sino también, según dice, el impacto sobre la vida laboral de Alejandro:

"Nunca tuve un conflicto en que yo fuera preparada y él no hubiera cumplido con sus estudios. Lo hablé con mi papá, inclusive, en un momento y se lo dije: 'tenemos una cierta desventaja por lo que no es conveniente que se venga a México, por esta falta de preparación'. (...) Inclusive él me decía: 'yo voy'. Pero las oportunidades no las tenía, el horario... no parar en casa a mediodía, trabajar los sábados...entonces 
no daría para pagar el piso en México, el crédito de aquí.. (...) Con el tiempo ya acordamos que iríamos a vivir con su madre un año hasta que nos estabilizáramos..."

- Liz (Cuba, 35), trabajando en un centro de investigación de la universidad tuvo oportunidad de conectarse a Internet (algo difícil en Cuba) y conoció a Jordi (España, 40). Siempre tuvo claro que si la relación cuajaba, sería ella la que migraría:

"Pero es que aunque él decida irse para allá (Cuba), y empiece a trabajar allá... en una escuela como profesor no le van a pagar como le pagan aquí... Te haces la ilusión. Como no te está permitido salir del país, la ilusión de salir... de conocer otro lugar".

Y Jordi, por su parte, también:

"Con lo que tú me estás explicando, yo ya puedo decirte que en Cuba no nos podemos quedar a vivir. Yo no me opongo a irme a vivir a tu país, si no es por las condiciones económicas. Y si yo me voy a vivir de España a otro país, quiero decir que económicamente, la base de la vida... debo estar económicamente mejor que en España y desde luego en Cuba ni tú ni yo. Por tanto si la relación va a seguir y no sé qué, es mejor ir a España".

Las mujeres del "sur global" que dejan su país para realizar un matrimonio mixto con un español citan a menudo el dolor y la tristeza por dejar su país, pero se muestran en general convencidas de la decisión tomada, si bien sus circunstancias son diversas. La situación laboral de Sonia, Chivis y Liz en el momento de tomar la decisión era buena, con un trabajo estable y relacionado con sus estudios universitarios previos. A pesar de ello, Sonia, cuyo cónyuge tiene una formación académica inferior a la suya, ni se planteó la posibilidad de que fuera su futuro marido el que emigrara. Chivis, Liz y Xuelin, -quien más explícitamente manifestara su deseo de quedarse en su país y de que fuera su marido quien emigrara- sí que plantean tal opción, pero solo para llegar a la conclusión de que sería difícil para sus maridos encontrar trabajo en China, México o Cuba respectivamente. Akane y Sol, por su parte, aun teniendo clara la decisión de emigrar al país de sus futuras parejas, negocian una prórroga para cancelar adecuadamente algunas cuestiones pendientes que tiene que ver con la preparación laboral y con el mantenimiento de ciertas garantías laborales en caso de retorno al país, como finalizar adecuadamente un contrato de trabajo, preparar a la familia o acabar sus estudios.

\section{2.- Origen: España}

- Carmen (España, 48), después de divorciarse de un primer marido francés con el que se había casado con 23 años, conoció a su actual marido (México; 42) en un viaje por Egipto. Ella trabajaba como profesora de enseñanza secundaria y traductora en una ciudad del Levante español. Deciden casarse y que él, ingeniero electrónico, venga a vivir a España. Pero Carmen se queda embarazada y su novio decide no casarse y quedarse en México. 
A las pocas semanas él empieza a pedirle que ella se vaya a su país:

"Y él todo el rato: 'Vente para acá, que yo quiero estar contigo, ique no sé qué!'. Y yo: 'Yo no puedo, yo tengo aquí mi casa, tengo aquí mi trabajo'. Y así estuvo todo el embarazo. Ah, porque fue, y no solamente fue, sino que además buscó trabajo y encontró trabajo, en Pemex. '¡Ah, que tengo un trabajo muy bueno, que vamos a vivir muy bien!', me llama la madre también. Y yo no, no. (...) Y ya nació la niña en julio y a los dos meses nos casamos y ya me vine para aquí (México). Pero yo siempre pensado en volver. Hasta se le ocurrió decirme: 'Mira en México se hace mucho los bienes separados, no sé qué, y yo le dije ¿¿Tú me has visto cara de tonta o qué? Me voy a ir a vivir a México, voy a dejar mi trabajo, mi familia, mi país, mi casa, ;con una inseguridad así! No, no. Yo llego aquí y es como un contrato, es un contrato'... yo no voy a irme allí desamparada. De todas formas yo tenía mi excedencia por tener un hijo menor, y en el momento que yo quiera yo puedo regresar. Y si no llega a ser por eso, creo que yo no me vengo".

-Núria (España, 46), ingeniera eléctrica, y su marido (México, 49) se conocieron en la Universidad Politécnica de Cataluña, donde ambos estudiaban. Cuando acabaron la carrera, él intentó trabajar en España durante un tiempo, aprovechando los contactos que tenía, pero no funcionó y decidieron irse a México, aunque no lo decidieron solos:

"Bueno, de todas formas a nuestras familias les parecía mejor que fuéramos a México... En realidad las oportunidades para una persona que quiere ser empresario son muy diferentes en México y en España. México es un país muy emprendedor, en cambio montar una empresa en España... Vinimos a México por razones laborales. A mí me era igual empezar allá o aquí. Cuando estuve aquí (México) ya no me pareció tan igual..."

-Victoria (España, 32), economista, conoció a su marido (Brasil, 36) en la empresa multinacional de Barcelona, donde ambos trabajaban. En un momento dado, cuando aún solo eran amigos, él decide regresar a Brasil. Siguieron teniendo una cierta relación y él le invitó a ir a Brasil. Victoria, que estaba molesta porque nunca se lo había propuesto, se decidió:

"Al final me dijo: 'Es que la verdad es que te echo mucho de menos.' Entonces él ya había conseguido aquí [en Brasil] un trabajo, un piso donde vivir, y entonces me dijo: 'Bueno, ahora, si quieres venir...' ¡Y entonces vine! Pedí una excedencia de un año, por si acaso... ¿no? nunca se sabe... Pero ya ha pasado ese año y no he vuelto, así que ya la he perdido. Pero sí, no sé. Lo comenté allí en el trabajo, con mi jefe: 'Oye, mira, hay esto, así que me, me voy, y... no sé, voy a la aventura, un poco. Ya veremos'. Y bueno, todo el mundo diciendo que era estupendo 'Sí, sí, vete, porque total aquí en España que... qué vas a hacer, ¿no?' (...) Y entonces pensé: 'Bueno, si me tengo que 
ir, ahora es el mejor momento. En España está todo parado y según las noticias aquí en Brasil está todo zumbando, pues ¿por qué no?' Y que... bueno, yo alquilaba una habitación. No tengo hipoteca, no tengo niños, no tengo responsabilidades ningunas con respecto a nadie..."

Victoria no se lo piensa dos veces, pero es perfectamente consciente que la decisión es suya y que es ella la que elige iniciar una relación y asume los costes:

"Yo, en ese momento no era suficiente [razón] para que él se quedara [en Barcelona]. Él había tomado la decisión de volver [a Brasil] y yo ni siquiera entraba en esa decisión. Era en plan: '¡Me tengo que ir! ¡Me voy, me voy! ¡Ya no puedo más!' Y ya está. Y se vino. Y después fue: 'Voy yo.' No sé.

-Amelia (España, 35) trabajaba como arquitecta para la administración pública cuando conoce a André (Brasil, 40), su actual marido. Simultáneamente empieza a padecer los recortes y una crisis en su trabajo. Tras varios intentos fracasados de conseguir que su novio viniera a vivir y a trabajar en España, decide irse a Brasil:

"Yo creo que cuando conoces a tu pareja extranjera en tu país, yo creo que una de las cosas que te hace irte al otro país es que tú no puedes conseguir trabajo para ella, ¿sabes? Porque yo he visto situaciones comunes donde la idea era quedarnos en España o en Europa al menos, pero como su pareja en ese momento, en un contexto de crisis, se veía una perspectiva mínima de encontrar trabajo, yo tampoco me estoy viendo una continuidad muy clara, y en cambio él en este caso (ahí no sé si es cuestión de sexos o no), pero sabíamos que él sí podía encontrar un buen trabajo con sueldo bueno y tal. Yo, como muchos otros, queremos volver, porque se vive muy bien en España y Europa en general. Si pudiese escoger, antes prefiero vivir por Europa que por aquí [Brasil], pero bueno, en fin, que lo del trabajo era bastante clave en la decisión de venir para aquí, y yo creo que a mucha gente le habrá pasado".

- Rita (España 36) es comadrona y durante muchos años su plan de vida era trabajar nueve meses y viajar los tres restantes del año. Nunca tenía problemas en encontrar trabajo en España. Un buen día conoce a su pareja (Brasil, 49), un profesor de universidad que estaba en Barcelona realizando el doctorado. Estaba claro dónde pasaría sus próximos tres meses de vacaciones. Y ya también intuía que probablemente no serían solo tres meses:

"Es una persona estable, ¿sabes? Por un lado es una persona estable, él tenía su trabajo, tenía sus cosas allá, o sea, que yo era un poco, hacía un poco de loca de dejar las cosas, lo mío, pero bueno, él tenía una estabilidad, ¿sabes? Yo dejaba, pero bueno, no es que me fuera... Yo pensaba así: 'No es que me voy aquí, al vacio', ¿sabes? Él tiene una estructura y tal, ¿no? Entonces, por un lado así, pero por otro lado, pues eso, que tiene mucho sentido del humor, y que lo principal en su vida no 
es solo trabajar, trabajar, trabajar, ¿no? Es vivir, es disfrutar y esas son cosas que a lo mejor... Bueno, luego viendo entre las dos culturas, ¿no? cómo se vive tan diferente ¿no? pero allí la gente tiene más tiempo de mirarse a los ojos, de hablarse, de estar el uno con el otro... y no tanto de producir, producir, producir, ¿sabes? Que esto a mí ya me cargaba desde el principio, porque fíjate que yo trabajaba nueve meses y decía ‘YYa no puedo más! ¡Me voy!' ¿Sabes? Ya iba un poco en mi línea, ¿sabes? Yo todo esto no me cuadraba, nunca me ha cuadrado mucho todo este sistema de producirtrabajar-producir-trabajar, pero ¿para qué? ¿No? Y entonces en eso coincidíamos bastante."

-Beatriz (España, 45) es consultora-investigadora. Conoce a su actual marido (República Centroafricana, 41) en Mali, en el marco de una investigación. Después de cuatro años viviendo y trabajando en distintos países de África, regresa a España para dar a luz, a donde también viaja su marido unos meses después, para realizar un máster y el doctorado en Farmacia. Pasan dos años en España y después, acompañando a su marido, viven unos tres años en la República Dominicana para regresar posteriormente, tras un breve paso por España, a la República Centroafricana, donde viven desde hace seis años. No hubo, en este caso, decisión sobre dónde vivir. Esta ya estaba clara desde el inicio, tanto par Beatriz como para su marido:

"Pero lo que estaba claro era que íbamos a volver a África, y que íbamos a volver a Centroáfrica. Antes de venir a España jeso estaba claro! Y además, mi marido me lo dijo, o sea "iQue sepas que yo nunca me quedaré en Europa!". Él es una persona que no había pensado en su vida, nunca, venir a Europa, ¿eh? Quiero decir, que no tiene un sueño de venir a Europa para... cumplir ese sueño. $Y$ ha sido un poco también el trabajo de él el que ha marcado la... itinerancia, ¿no? Yo luego me iba adaptando a hacer investigación, bueno, yo seguí haciendo mis investigaciones $y$ eso, pero sí, no, ha sido el trabajo de él, que es el que lo tenía más difícil. Más difícil aunque no por formación, pero sí por su... origen. Yo también lo tenía claro. Lo que igual no tenía tan claro era si me quería quedar en $R$. Centroafricana o... en Mali, ¿eh? pero lo que tenía claro es que yo quería estar en África también, o sea que... Eso no había problema. A mi marido, todo el mundo le decía "Ya verás, cuando vengas a Europa... jte vas a querer quedar!" Y ni loco, jvamos! ¡No quiere quedarse ni loco! [se ríe] Y yo le entiendo, ¿eh?, que no quiera quedarse en Europa".

Las mujeres españolas que deciden emigrar para vivir en el país de origen de su pareja manifiestan, excepto en el caso de Núria, Beatriz y, en menor medida, Rita, ciertas reticencias iniciales que se proyectan en un deseo más o menos fantasioso de regresar algún día a España o -al menos- de dejar la puerta abierta a este retorno. Carmen y Victoria piden y van renovando la excedencia laboral de sus trabajos en España, algo que no encontramos entre las mujeres extranjeras migrantes por amor a España. Carmen y 
Amelia incluso intentan en primera instancia iniciar la vida de pareja en España, pero ambas acaban cediendo. Todas nuestras protagonistas españolas argumentan y justifican en gran medida su decisión basándose en las mejores perspectivas laborales para sus parejas masculinas, tal como hicieran algunas de las mujeres extranjeras de parejas mixtas con españoles que hemos visto antes. El marido de Carmen había encontrado un muy buen trabajo en México, aunque ella tenía un trabajo estable aquí; el de Núria tenía muchas más posibilidades de montar una empresa en México que en España; el de Amelia y el de Beatriz aquí solo iban a encontrar trabajo no cualificado, mientras que el primero podría hallar un buen trabajo y un buen sueldo en Brasil, y el segundo, -uno de los 20 farmacéuticos que hay en República Centroafricana- es el dueño de una de las 18 farmacias que hay en el país y había sufrido discriminación debido a su origen en sus trabajos en España. El marido de Rita, por su parte, aportaba una estabilidad y calidad laboral que se contraponían a su vida laboral flexible e insatisfactoria; algo que encontramos también en Victoria, que a pesar de tener un buen trabajo en España, igual que Carmen y la misma Rita, empieza a padecer el empeoramiento de las condiciones laborales por efecto de la crisis. Tanto Victoria como Carmen, que son las que más estabilidad laboral tenían en España, comparten episodios de malestar previo con sus futuras parejas extranjeras - una por el abandono de él durante el embarazo y la otra por la resistencia de él a invitarla a viajar a Brasil. Sin embargo ambas, junto con Rita, deciden irse "sin pensárselo dos veces" cuando sus novios cambian de actitud. Núria es tal vez la más "atípica" de las seis mujeres consideradas: a ella le daba igual empezar en España o en México y, además, ambas familias de orientación les aconsejan que fueran a vivir a México. Sin duda el hecho de que Núria haya tomado la decisión de irse a vivir fuera de España hace ya 20 años -en la década de los '90- y que no tuviera entonces un trabajo son elementos a considerar en esta diferencia.

\section{3.- Viaje de ida y vuelta}

- Georgina (México, 44) conoció a su marido (España, 39) en un viaje turístico a Cuba, cuando llevaba diez años trabajando como abogada en los tribunales de México DF, y "lo dejó todo" -incluso las voces que le decían que cometía un grave error- para venir a vivir a España, donde en diez años jamás le convalidaron su título de abogada, tuvo dos hijos y combinó las tareas domésticas con ayudas puntuales al negocio de su marido, y trabajos esporádicos de limpiadora en el sector turístico y reponedora en centros comerciales. En el momento de entrevistarla, llevaba cuatro meses viviendo en México DF, a donde se había trasladado la familia después de que su marido hubiera agotado su prestación por desempleo en España. Cada día salía de casa en búsqueda de trabajo:

"El problema es, como me decían mis jefes: ¿'Te vas a ir? ¿De verdad? Piénsalo, míralo. No por casarte vas a perder todo lo que tienes, toda tu experiencia, todo tu tiempo...' 'No, yo me caso...' 'No, es que mira, es más importante...' ‘No, no! Para 
mí es más importante la familia.' ¡Y claro! En ese momento Francisco estaba muy bien. Y él me decía: 'Noooo, ¡estoy muy bien! ¡No necesitas nada de esto! ¡Vámonos! ¡Déjalo!' Y yo decía ‘No, pero cómo me voy a ir?’ Y, de hecho nos casamos... y él se fue. $Y$ regresó como a los... cuatro meses, me dice: 'No, la verdad es que no así. $O$ te vienes conmigo, o te vienes conmigo.' Allí fue que yo renuncié... La verdad es que eso fue muy loco, porque nos casamos y nunca nos planteamos ni él ni yo si íbamos a vivir allá, o si íbamos a vivir aquí... ;Y se nos olvidó todo! ¡Y claro! Cuando vino él, la situación... fue muy complicada porque... él nunca quiso venirse a vivir aquí, y yo fui la que tuve que renunciar, ¿no? Y así fue muy... de hecho, pues, mi casa se quedó cerrada diez años..."

- Marta (España, 36) es licenciada en Filología hispánica. Conoció a César (México, 49) en unas fiestas populares en España. Tras un noviazgo en la distancia, ella fue a pasar unos meses a México, donde se consolidó la relación. Ella se plantea: "Yo me fui con una maleta... Entonces, como que... pensé: 'Bueno, ¿qué vamos a hacer?' Él tenía un buen trabajo allá, yo no. 'Es más fácil que yo me quede en México...". Pero Marta, tras tres años en el DF, y consiguiendo trabajo como editora y dando clases de catalán, sintió: "la ciudad se me viene encima... Yo aquí no.... no me veo viviendo toda la vida. César quería tener hijos, yo ahí no me veía..." y entonces decidió, con su marido, un alto directivo de la administración pública mexicana, regresar a Tarragona, donde ella trabaja en dos sitios diferentes y su marido encadena períodos de trabajo no cualificado con períodos de paro.

Nuestras dos informantes, que realizan un viaje de ida y vuelta entre su país de origen y el de su pareja, con sus períodos de estancia respectivos -nueve años de residencia en el extranjero para la mexicana Georgina y tres años de residencia en el extranjero para la española Marta-, tienen en su trayectoria tanto elementos comunes como diferenciales con los otros dos colectivos que hemos presentado anteriormente. Así, Georgina, como muchas de las otras mujeres del "sur global" entrevistadas, "lo deja todo": un trabajo cualificado y estable, una familia, amigos, y un piso en propiedad en el DF mexicano. $\mathrm{Y}$ esto para casarse con un marido español con un nivel de estudios muy inferior al suyo y un trabajo no cualificado, con temporadas en el paro, e ir a vivir a un pueblo de la costa mediterránea. Si en la decisión de salir de su país las consideraciones laborales propias no tienen ningún peso, en la decisión de retornar a México, por el contrario, son fundamentales. Ella emigra a España por amor por su marido Francisco, y regresa a México después de nueve años por su marido también, que es quien toma la decisión de viajar a México debido a su precaria situación laboral. Ella no quería regresar a México, a pesar de la situación de paro de su marido y la suya propia, sin trabajo también y con nulas perspectivas laborales. Tal vez su resistencia tenga relación con el hecho de tener que enfrentarse a las voces que en el momento de su partida le advertían de su "locura" y 
con la conciencia de los cambios que supone pasar de vivir en una pequeña localidad de apenas 30.000 habitantes a una megalópolis de más de 20 millones, con las repercusiones correspondientes en la vida de su pareja e hijos. Esta dureza de la vida en el DF mexicano, precisamente, no es ajena al itinerario de Marta, nuestra segunda informante, quien decide emigrar a México, donde vivía su futuro marido, por motivos laborales: la buena posición laboral de él y su propia carrera profesional incipiente. Creía que era lo mismo comenzar su carrera en España que en México. Pero después de unos años, y ante su inadaptación a la vida en ciudad de México y el proyecto recurrente y cada vez más fuerte de tener hijos, decide hacer realidad lo que para muchas de las entrevistadas es solo una posibilidad más o menos remota: volver a España. Esta decisión no se produce por motivos laborales. De hecho, Marta no tenía trabajo estable en España cuando emigró, ni tampoco cuando decide volver y, por otra parte, consigue trabajos bien satisfactorios en el DF. En esta pareja, el retorno de Marta tiene consecuencias laborales muy negativas para su marido, que es quien "lo deja todo", algo que en las otras parejas presentadas en esta investigación ha sucedido, pero para las esposas.

Ya hemos visto cómo la decisión de emigrar afectó a la situación laboral de nuestras protagonistas en aquél momento. Veamos, a continuación, cómo incidió en su trayectoria laboral posterior en destino.

\section{4.- TRABAJAR O NO TRABAJAR}

No es fácil abandonar el país de origen por razones no laborales y solucionar de forma rápida y satisfactoria la situación laboral en el país de destino. Muchos de los países del denominado sur global desde hace un tiempo han empezado a endurecer las condiciones legales de acceso al trabajo de las personas inmigrantes, emulando y/o respondiendo de este modo a las políticas de control de inmigración y acceso al trabajo presentes desde hace varios años en los países del "norte global". Nuestras protagonistas no han sido ajenas a esta situación, aunque ellas pertenecen a un grupo menos desfavorecido que el de los inmigrantes estrictamente económicos por dos razones: a) porque el matrimonio con un nacional les otorga una serie de ventajas legales que les simplifica, entre otras cosas, el acceso al mercado laboral; $\mathrm{y} b$ ) porque este mismo matrimonio les facilita una red social y profesional -la del marido-, acrecentando así sus probabilidades de incorporación a ese mercado. Pero como todas nuestras protagonistas son mujeres cualificadas, se encuentran con una dificultad suplementaria respecto a otras inmigrantes, ya que muchos países dificultan y/o imposibilitan la convalidación de títulos académicos extranjeros (McKay, 2003; Man, 2004: 141; Purkayastha, 2005: 188).

La mayoría de mujeres del "sur global" que constituyen la muestra vinieron a España ya casadas o se casaron nada más llegar. Entre nuestras informantes españolas emigradas, en cambio, hay diversidad de situaciones: varias de ellas no planeaban casarse necesariamente, aunque la mayoría acabó oficializando la relación, entre otras cosas porque les facilitaba 
el trámite de la residencia y ganaban en términos de acceso al trabajo, tal como fuera señalado para otros países (Piper y Roces, 2003: 17). Por ejemplo, cuando Marta no pudo renovar más su visado de turista en México, se casó " $y$ al poco tiempo encontré trabajo". Victoria, por su parte, se casó en Brasil en mayo de 2012, obteniendo así el permiso de trabajo, y en noviembre del mismo año comenzó a trabajar. Según sus palabras, "casarse lo facilita todo", tal como le había aconsejado un directivo de una multinacional catalana con el que tuvo una entrevista de trabajo: "...y él me dijo, así, claramente: 'Cásate. Cásate, olvídate de todo lo demás, y va a ser mucho más fácil'. Reconoce que también le favoreció el hecho de tener estudios y, sobre todo, el conocimiento de idiomas (habla español, inglés y alemán). Aun así, Victoria no ha conseguido trabajo acorde a su titulación: es economista y como tal trabajaba en Barcelona, mientras que en Río de Janeiro se encarga de la comunicación con los clientes extranjeros de un despacho de abogados. Lo mismo le ocurrió a Núria, ingeniera eléctrica, que desde su llegada estuvo trabajando diez años en México en el sector financiero, tiempo que tardó en convalidar su título y que coincidió con el momento en que adquirió la nacionalidad mexicana (trámite que hizo, según dice, para conseguir dicha convalidación). Esto le permitió trabajar en una empresa de su especialidad por cuatro años, al cabo de los cuales la confluencia de una reducción de plantilla y el nacimiento de su tercer hijo le llevó a abandonar la esfera laboral para dedicarse a la crianza.

En algunas ocasiones estas mujeres cualificadas sí consiguen encontrar trabajo acorde a su titulación, aunque muy a menudo las condiciones laborales no son comparables con las que tenían en sus trabajos en España. Es el caso de Amelia, arquitecta, que después de emigrar a Brasil para vivir junto a su pareja en Belo Horizonte decide buscar trabajo a $500 \mathrm{Kms}$., en Río de Janeiro, porque no le gusta Belo Horizonte y siente que en Río tendrá más oportunidades. La contrata un joven y pequeño despacho de arquitectura:

“...y la verdad que estoy contenta. La única pega es que cobramos mal, muy poco, ya te dicen: 'cartera de trabalho'. Yo cobro 3.000 reales, unos mil y poco euros. Estoy compartiendo piso con una pareja de brasileños, jeh! [su pareja sigue viviendo en Belo Horizonte], y pago 1.100 reales por la habitación...”.

En el caso de las mujeres cualificadas del "sur global" que emigran por amor al "norte global", este proceso de descualificación laboral se radicaliza, y las situaciones de paro son habituales. La cubana Liz, con dos años en España, aún no tiene trabajo remunerado. Lo mismo le sucede a la venezolana Sol, que se dedica a la crianza de su hijo; mientras que Chivis, que trabajaba en el sector bancario en México, hace cuatro meses que llegó a España y, despistada, según nos cuenta, por el paso del frenesí de la vida en el DF a la de una ciudad de provincias, está aprendiendo a ejercitarse como ama de casa, tutelada por su suegra, con quien vive junto a su pareja: 
"Yo no estaba acostumbrada hacer las labores de la casa, porque como trabajaba, pagaba porque lo hicieran (...) No he tenido mucha iniciativa para cocinar porque no sé cocinar: me tengo que aplicar".

Irónicamente, mientras que algunas de estas mujeres originarias del "sur global" se casan internacionalmente para huir de los roles de género tradicionales (Roca, 2011), sufren una descualificación que, en muchos casos, las confina al nicho doméstico (Piper y Roces, 2003: 6).

De las que han conseguido trabajo, la japonesa Akane -quien no pertenece a lo generalmente denominado sur global- es la única que logró trabajar en un puesto con una cualificación similar a la de su país de origen. Después de un año en España en el que no pudo trabajar legalmente, y habiendo vivido una depresión que le llevó a irse un mes a Japón, en su segundo año consigue trabajo en un parque temático, gracias a los contactos de su marido. Esto, dice, le salvó y la recuperó emocional y anímicamente. Al finalizar la temporada se quedó embarazada y abandonó el trabajo para dedicarse a su hijo. Sonia (universitaria originaria de Perú), por el contrario, después de más de una hora de entrevista, nos confesó:

"Mi realización personal, de trabajo aquí... pésimo. Aquí estoy... estoy... no estoy contenta con el trabajo (...) Y este trabajo de estar así... entramos a las seis y a las cinco yo ya me estoy vistiendo. Empezamos a las seis y acabas a las dos de la tarde. A las seis de la mañana tienes que estar por las calles, limpiando. Creo que si yo hubiese venido sin nada, normal estuviera. Pero como detrás de mí he dejado un montón de cosas.... Y tú dices 'dónde están los seis años que he estudiado', me he quemado las pestañas, me amanecía y mi madre me traía mi cafetito, amanecía y haciendo tesis, yo he hecho una tesis. Y a veces digo yo: ¿Qué hago aquí, soy tonta, o qué me está pasando?"'.

Entre uno y otro extremo, encontramos a Georgina, la abogada mexicana, que en sus diez años viviendo en España realizó todo tipo de trabajos esporádicos no cualificados, desde limpiadora en el sector turístico a reponedora en centros comerciales.

En algunos de estos relatos hemos visto asomar la presencia de la esfera reproductiva interviniendo tímidamente en relación con la esfera laboral. Veamos a continuación cómo ha incidido la crianza de los hijos en las trayectorias laborales de nuestras protagonistas. Carmen, la filóloga y traductora española que emigró a México con su hija recién nacida, es sin duda la representante más genuina, entre las españolas, de dedicación exclusiva a la crianza de los hijos. Y Sol, la venezolana licenciada en Dirección y Administración de Empresas, su equivalente entre las inmigrantes en España. Carmen llegó a México hace diez años, teniendo claro que se dedicaría a la crianza de su hija porque su idea era regresar a España al cabo de tres años (con la familia) para reincorporarse al trabajo, del 
que había pedido excedencia. Transcurridos estos tres años, en España se había iniciado un período de crisis económica y su marido había alcanzado en México una muy buena posición laboral. Además, se quedó embarazada de su segunda hija:

"Pero aun así yo decía: 'Cuando las niñas entren en la secundaria, yo me voy seguro. La mayor tiene once años, está en quinto de primaria. Pero yo, como veo las cosas allí, ahora con la crisis está mal, ahora está peor. Él no va a encontrar un trabajo mejor. Y ya me acostumbré. Aquí como que tengo miedo, digo que llevo mucho tiempo sin trabajar y claro, ¿y dónde voy? Dar clase, tal y como están aquí las escuelas no me apetece, a parte que cobran fatal".

Carmen, muy crítica e irónica con las mujeres de su entorno en México, con las que comparte posición social y situación ocupacional de ama de casa y de las que dice que todas tienen la carrera de MMC -Mientras Me Caso-, ha renunciado tanto a regresar a su país como a volver a tener un trabajo remunerado.

Sol, por su parte, con 37 años, después de dos años sin conseguir tener "los papeles para poder trabajar", viviendo semiaislada en una urbanización "donde no hay nadie con quien irme a tomar un café", sin tener prácticamente relación ni con sus vecinas ni con las madres de la escuela de su niño, afirmaba:

"A mí me gusta estar aquí. Mis aspiraciones es que ahora que tengo mi residencia -porque como no podíamos casarnos no tenía mis papeles- pues ya me llegaron y ahora quiero trabajar... Porque no podía hacer otra cosa, porque siempre te piden el permiso de residencia: '¿Tiene usted el permiso de residencia?'... Y trabajar mucho menos, porque nadie te va a contratar si no tienes el permiso. Por eso estoy tan contenta, porque con esto voy a tener más oportunidades, se me van a abrir más puertas...”.

En otros casos la crianza de los hijos se compagina con el trabajo extradoméstico remunerado, a menudo con escasa participación de la pareja en la esfera reproductiva. Rita, la comadrona española de 36 años con un régimen de trabajo peculiar en España (nueve meses de trabajo a destajo y tres de viaje por el mundo), tuvo muy claro desde el principio que ella se dedicaría de forma prioritaria, casi exclusiva, a la crianza de sus dos hijos, y enfatiza en el carácter elegido de esta dedicación, en un escenario similar al descrito por Purkayastha (2005: 192):

"Vivíamos en Salvador, y nos fuimos a vivir a este pueblo, a esta ciudad, que es cerca del trabajo de él... Los niños estaban muy pequeños, y yo he querido, he elegido ¿sabes?, he elegido estar con ellos, entonces a mí no me incomoda nada, porque precisamente he podido estar con ellos sin tener la presión de que tengo un horario para entrar a trabajar y otro para salir. Eso lo tiene él. Yo me he acogido a ese rol tradicional. Él me dice: '¡Tú puedes trabajar! ¡Trabaja!', no sé qué. ¡Pero yo no 
quiero! Si yo trabajo, ¿quién se queda a cuidar de ellos?, ¿sabes? Están pequeñitos, y yo no quiero dejarlos en manos... ¿Cómo voy a dejar esto, que para mí es tan importante, en manos de alguien que no sé quién es?, ¿sabes? Entonces yo lo he elegido, lo he elegido".

El trabajo extradoméstico no aparece en el horizonte vital de Rita como una elección y una posibilidad real. Tan sólo como una distracción, y con un peso poco sustancial:

"Y yo empecé a buscarme como cosas, y digo: 'Bueno, a ver, ¿qué voy a hacer aquí que me guste y que...? ¿Qué voy a hacer yo aqui?', ¿no? Porque bueno, aquí es un país muy peligroso, la mujer está vista de una manera muy diferente que en España, las posibilidades de trabajo para mí eran... eran muy malas, ¿sabes? Entonces digo: 'Bueno, yo tengo que encontrar algo para mí que me enganche, que me guste', ¿no? Entonces fui buscando cosas... y sí, trabajo dando clases de español uno o dos días a la semana. Bueno, por salir a airearme, ventilarme, ¿sabes?"

En el caso de Beatriz, la mujer del País Vasco consultora-investigadora y esposa del farmacéutico de la República Centroafricana, ya vimos que no solo asumía sino que participaba de forma convencida y consensuada de la decisión de desarrollar la relación de pareja en el continente africano, como una forma de compromiso para con esa sociedad. Tanto es así que su actividad laboral se amolda a la de su marido, con quien colabora también en su ejercicio laboral. La tarea de crianza del hijo descansa casi exclusivamente en ella:

"Mi marido está en la farmacia... Yo también estoy en la farmacia, ¿eh?, hago la supervisión de la contabilidad, que no tiene nada que ver con mi formación. Cuando no estoy haciendo investigaciones sobre el terreno, estoy en la farmacia, pero yo estoy menos horas que él. O sea yo lo que hago es que yo estoy en la farmacia las horas que el niño está en el colegio. Y cuando él vuelve del colegio, yo me ocupo del apoyo escolar del niño. Tengo una persona que me ayuda en casa. Entonces digamos que las cosas de casa las hace esa persona y yo lo que hago es ocuparme de lo que es el apoyo escolar del niño. Y de organizar lo que tiene que hacer esa persona. Y cuando yo no estoy, que yo suelo estar investigando en... en cuatro esquinas del país, porque yo viajo por todo el país, pues, en ese caso es él".

Las tres últimas informantes españolas que hemos visto hasta aquí siguen un patrón más o menos común: trabajo en España acorde con su cualificación, y abandono de toda actividad laboral o compatibilización de la misma con la crianza de los hijos, que pasa a ocupar el centro de su actividad cotidiana. El resto de mujeres españolas emigradas que desarrollan una actividad laboral en los países de destino se caracterizan por no tener hijos. Podríamos decir que Núria, la ingeniera eléctrica emigrada a México hace ya dos décadas, es un caso intermedio. Llegó a México para casarse y trabajó durante 14 años, 
sin abandonar la actividad laboral por el nacimiento de sus dos primeros hijos. Esta decisión solo la tomó cuando nació el tercero.

Estos itinerarios laborales de mujeres españolas cualificadas emigradas no difieren mucho de los de sus compatriotas no emigradas. Tal vez la diferencia sea tan solo una cuestión de grado que tiene que ver con la edad, las características de la sociedad de destino y con la especificidad del contexto migratorio. Núria, que junto con Carmen, es la única mujer española de la muestra que se halla en la cuarentena -el resto están entre los treinta y los cuarenta años-, forma parte de una generación socializada en la importancia del trabajo extradoméstico como mecanismo de igualdad e independencia económica. Las mujeres más jóvenes ya han crecido con esta premisa incorporada de una forma tan clara que ni se la plantean, ni tienen la necesidad de defenderla de una forma militante. Por esto, tal vez, lo que influye y determina más sus decisiones en relación a la crianza de los hijos y el trabajo remunerado es el entorno migratorio en el que se hallan inmersas, caracterizado por la falta de una red social de apoyo y las dificultades para encontrar un trabajo acorde a su preparación y formación profesional.

Para acabar nuestro recorrido, los casos híbridos de Georgina y Marta nos aportan unos escenarios particulares. La mexicana Georgina, después de pasar una larga temporada en España con trabajos precarios y no cualificados, regresó a su país con su familia, por decisión de su marido español, que se hallaba desde hacía tiempo en el paro. Las expectativas laborales al regresar eran poco alentadoras:

"Mi idea al llegar aquí a México fue: 'Tengo diez años en el vacío', y eso, quieras que no, a cualquiera le pesa. Y yo decía 'para que yo encuentre trabajo va a estar muy difícil porque yo, sí, sí, mucho derecho, mucho abogada, lo que tú quieras, ipero a la gente le importa que tú estés activa!' Y más que aquí reformaron la ley laboral. Entonces ahí fue donde yo decía: 'No, no, no me van a llamar'”.

Al día de hoy, con dos hijos de nueve y cuatro años, está buscando volver a incorporarse al mercado laboral de su país. Cree que las posibilidades de que su marido - un trabajador no cualificado- logre hacer lo mismo son escasas. Y las de que se implique, como nunca hizo, en las tareas de reproducción, simplemente improbables, lo que determina el tipo de trabajo que ella entiende que debe buscar:

"Lo que yo quiero es un trabajo donde yo pueda compartir con mis hijos momentos, ¿no? El hecho de a la tarde poder estar con ellos, hacer la tarea... Y no irme en la mañana y regresar a la noche y que no me vean, ¿no? Y además, al venir aquí -a México-, como que están cambiando un poco los papeles, y sí, es como que yo siento que... Dicen que los mexicanos son machistas, ¿no? Y yo lo veo más... Comparado con los españoles, ¿no? Como que a Francisco le ha costado mucho el tener que admitir que esta vez a lo mejor soy yo la que puedo tirar del carro, ¿no? Y le cuesta 
mucho, ¿eh?, parece que se le está cayendo el mundo encima, ¿no? Le digo. 'Pues no tiene nada de malo, ¿no? Nosotros somos una pareja, una familia, y para eso estamos, ¿no?' Le cuesta... Hace poco tuvo un comentario así, medio raro. Estaba barriendo, $y$ fregando el suelo y dice. 'Ahora ya nomás falta que me graben y me pongan en Facebook, porque estoy fregando el suelo', ¿no? Lo habrá dicho en broma o no, pero a mí me sonó como diciendo 'Estoy haciendo el ridículo' iY no es así! Allá -en España¡no movía un dedo! Él siempre llegaba y todo lo encontraba perfectamente”.

En la pareja de la española Marta y del mexicano César se cambian radicalmente los papeles en comparación con el caso anterior. Se invierte la nacionalidad y el género de los protagonistas, y también el itinerario migratorio. $\mathrm{Y}$ aunque estructuralmente se dan situaciones parecidas -la mujer que retorna se encuentra en una mejor posición para incorporarse al mercado laboral de su país que no su marido extranjero- la respuesta masculina también aparece en un sentido radicalmente inverso en uno y otro caso:

"Bueno, eso [que César no haya podido convalidar los estudios, que haya tenido que buscar trabajo de otra cosa, y que esté en el paro] ya lo sabíamos de alguna manera. ¡César tenía un buen trabajo! Su carrera aquí no se la convalidaban. César llegó un día que me dijo: 'Si tú aquí no vas a estar bien, yo no voy a estar bien.' Dice: 'Voy allá, y aunque tenga que descargar camiones, de algo trabajaré.' Dijo: ¿'Tú tienes que hacer el CAP? ¡Ve y hazlo! Yo vine, me apunté al CAP, viví con mis padres, y la primera semana tuve una entrevista de trabajo en una empresa, de profesora de español para extranjeros. Y me dieron el trabajo. Lo combiné con un trabajo de fin de semana, reponiendo y de cajera, y después me iban saliendo más clases por la mañana, en academias y así. Hasta que me llené todo el horario. Y en cuatro meses acabé el CAP, hice la memoria y todo eso, y en abril ya vino César. Hubo mucha gente [de México] que le decía: ' $i$ A ti no te van a querer ni de pintor!' Que eso dices: '¿Qué desagradable que os valoréis tan poco!' O sea... por el simple hecho de ser mexicano, ¿no? Que se valoren tan poco. Trabajó de consultor y comercial, y después de técnico de compras. Se sacó un título de técnico de compras aquí, de una agencia española. Claro, no puede opositar a un trabajo de licenciado, pero tampoco hay oposiciones, o sea que... (...) [sobre el reparto de tareas domésticas] Nunca nos hemos dicho: 'Tú haces esto; yo hago lo otro', pero más o menos vamos tirando. Pero básicamente, él se encarga del súper, cocina y todo eso, y yo de ropa, lavadoras.... Y lo demás... ¡A ver quién lo hace! [risas] Y luego llegó el niño. Lo cuida él, porque al estar desempleado, es papá completo, día completo."

En general constatamos que la mayoría de nuestras protagonistas se debaten en torno a fuerzas antagónicas que, por un lado, les impulsan a continuar, tras el proceso migratorio, su carrera laboral en la misma dirección que la había llevado en el país de origen y, por otro lado, les redirigen hacia una mayor o incluso exclusiva orientación a la crianza de 
los hijos. En el primer caso podemos afirmar que su elevada preparación profesional y su experiencia laboral previa relacionada con esta preparación son los principales argumentos, en tanto que para el segundo caso, su migración de naturaleza no laboral sino amorosa, su condición -a pesar de todo- de inmigrantes, y en algunos casos también su edad, que las sitúa en fases "críticas" de la reproducción biológica, serían los principales elementos a tener en cuenta.

\section{5.- CONCLUSIONES}

A lo largo del artículo hemos presentado a las 14 mujeres que conforman la muestra con la que hemos trabajado y sus correspondientes itinerarios vitales. Todas nuestras protagonistas tienen en común que son mujeres cualificadas, con estudios universitarios, y que en un momento dado conocieron a un hombre de otra nacionalidad, que vivía en otro país, con el que decidieron iniciar una relación de pareja que supuso su emigración al país de su pareja. Otro elemento común del colectivo estudiado es su relación directa con España, que es el país desde donde emigraron o al que emigraron. Hemos abordado, pues, un colectivo con algunas características generales compartidas que podemos subdividir en dos grupos: el conformado por mujeres que realizan una emigración del "sur global" al "norte global" - un colectivo ampliamente estudiado, aunque no en relación a las mujeres cualificadas- y el compuesto por mujeres cuyo itinerario migratorio es inverso, del "norte global" al "sur global" - muy escasamente considerado en la literatura científica.

Nuestro foco de interés se ha centrado en la experiencia laboral de nuestras protagonistas. Los hallazgos concuerdan parcialmente con lo que otros autores y autoras han señalado en estudios con parejas migrantes de la misma nacionalidad formadas por personas cualificadas. Pero también matizan estos hallazgos previos y aportan datos novedosos, especialmente en relación al subgrupo de mujeres cualificadas del "norte global" migrantes por amor al "sur global".

El análisis del conjunto de realidades presentes en las componentes de la muestra debe abordarse en términos interseccionales, teniendo en cuenta el cruce de variables fundamentales como la edad, la presencia o no de hijos, la nacionalidad de nuestras protagonistas y de sus cónyuges, el nivel educativo y la clase social de sus parejas, los años de convivencia, así como el sentido y la duración de la migración (de norte a sur o de sur a norte).

Un aspecto muy relevante es la constatación de que las mujeres entrevistadas toman sus decisiones relegando a un segundo plano sus proyectos laborales, y primando los de sus cónyuges. La sombra de la segregación de género en base a la polaridad producciónreproducción parece que sigue siendo alargada. Así pues, en las mujeres parece que el amor relega a un segundo plano el trabajo remunerado, en tanto que en la mayoría de los hombres parece que ocurre lo contrario. Muchos de los maridos impusieron a sus 
futuras esposas, de forma más o menos directa, la emigración de ellas para continuar la relación sentimental. Como proponen Lee y Piper (2003: 133), esto ubica en una posición de ventaja a los hombres, quienes están "en su propio territorio", mientras que las mujeres no están familiarizadas con esa cultura y (a veces) tampoco con el idioma. Como consecuencia, el "capital social y cultural" de las mujeres "se devalúa", mientras que "el de sus esposos se mantiene intacto" (Riaño et al, 2015: 161). Por esto muchas de nuestras protagonistas dejaron por amor una buena posición laboral y, en todos los casos, la empeoraron con su emigración, condicionando su carrera profesional.

En resumen, la investigación muestra el impacto negativo en las carreras profesionales y un crecimiento de la carga de trabajo doméstico para las mujeres entrevistadas. En cuanto al empleo, las consecuencias se centran en el descenso de la movilidad ocupacional, la disminución de ingresos, la mengua de la perspectiva de desarrollo profesional, la redirección de la carrera en términos de reorientación y la aparición del subempleo o el desempleo. En lo referente a la vida familiar, el impacto se mueve en un rango que va desde el aumento de las responsabilidades de la casa y/o el cuidado de los hijos a la completa inmersión en la esfera doméstica. En el primero de los ámbitos citados la condición de migrante cualificada se muestra más relevante que la de género. En el segundo, en cambio, el género tiene un mayor peso que la condición de emigrante, como bien se ejemplifica en las experiencias de los maridos de aquellas dos protagonistas que realizaron una doble migración. En definitiva, aquello que se constata en los términos más extremos, es un proceso de transformación de una mujer profesional cualificada en ama de casa, y de una mujer autónoma financieramente a una dependiente de su marido. Aunque la emigración del norte al sur, unido a la presencia de una pareja con igual formación superior, se traduce en mejores oportunidades laborales que la emigración de sur a norte al encuentro de una pareja con menor nivel educativo. 


\begin{tabular}{|c|c|c|c|c|c|c|c|c|}
\hline NOMBRE & $\begin{array}{c}\text { EDAD } \\
\text { Ego/Pareja }\end{array}$ & $\begin{array}{c}\text { PAÍS DE ORIGEN/PAíS } \\
\text { DE DESTINO }\end{array}$ & FORMACIÓN & $\begin{array}{c}\text { OCUPACIÓN EN } \\
\text { ORIGEN, ANTES DE } \\
\text { MIGRACIÓN }\end{array}$ & $\begin{array}{l}\text { OCUPACIÓN EN } \\
\text { DESTINO }\end{array}$ & OCUPACIÓN CÓNYUGE & HIJOS & AÑOS CONVIVENCIA \\
\hline Victoria & $32 / 36$ & España/Brasil & Univ./Univ. & Economista & Contable & Gerente & 0 & 4,5 \\
\hline Amelia & $35 / 40$ & España/Brasil & Univ./Univ. & Arquitecta & Arquitecta & Directivo & 0 & 4 \\
\hline Rita & $36 / 49$ & España/Brasil & Univ./Univ. & Comadrona & $\begin{array}{l}\text { Ama de casa/ } \\
\text { Profesora }\end{array}$ & Profesor Univ. & 2 & 5 \\
\hline Carmen & $48 / 42$ & España / México & Univ./Univ. & $\begin{array}{l}\text { Traductora/ } \\
\text { profesora }\end{array}$ & Ama de casa & $\begin{array}{l}\text { Subsecretario de } \\
\text { Energía }\end{array}$ & 2 & 11 \\
\hline Núria & $46 / 49$ & España / México & Univ./Univ. & Ingeniera eléctrica & $\begin{array}{l}1 \text {-Empleada de } \\
\text { banca } \\
\text { 2- Ama de casa }\end{array}$ & Ingeniero eléctrico & 4 & 20 \\
\hline Beatriz & $45 / 41$ & $\begin{array}{l}\text { España/República } \\
\text { Centroafricana }\end{array}$ & Univ./Univ. & $\begin{array}{l}\text { Consultora/ } \\
\text { Investigadora }\end{array}$ & $\begin{array}{l}\text { Consultora/ } \\
\text { Investigadora }\end{array}$ & Farmacéutico & 1 & 12 \\
\hline Marta & $36 / 48$ & $\begin{array}{l}\text { España/México/ } \\
\text { España }\end{array}$ & Univ./Univ. & $\begin{array}{l}\text { Estudiante/ } \\
\text { trabajos } \\
\text { esporádicos }\end{array}$ & $\begin{array}{l}\text { Correctora- } \\
\text { editora/profesora }\end{array}$ & $\begin{array}{l}\text { Directivo } \\
\text { Administración } \\
\text { Pública }\end{array}$ & 1 & 11 \\
\hline
\end{tabular}




\begin{tabular}{|c|c|c|c|c|c|c|c|c|}
\hline Georgina & $44 / 39$ & $\begin{array}{l}\text { México/España/ } \\
\text { México }\end{array}$ & Univ./F.P. & Abogada & $\begin{array}{l}\text { Trabajos } \\
\text { esporádicos no } \\
\text { cualificados/Ama } \\
\text { de casa }\end{array}$ & $\begin{array}{l}\text { 1.-Encargado } \\
\text { obras } \\
\text { 2.-Paro }\end{array}$ & 2 & 10 \\
\hline Liz & $35 / 45$ & Cuba/España & Univ./Sup. & Estadística & Paro/Ama de casa & Músico & 0 & 2 \\
\hline Chivis & $30 / 39$ & México/España & Univ./Elementales & Banca & Paro & Obrero & 0 & 0,4 \\
\hline Sol & $37 / 41$ & Venezuela/España & Univ./Secundarios & $\begin{array}{l}\text { Administración de } \\
\text { empresas }\end{array}$ & Ama de casa & $\begin{array}{l}\text { Sector } \\
\text { inmobiliario }\end{array}$ & 1 & 2 \\
\hline Sonia & $35 / 37$ & Perú/España & Univ./F.P. & Educadora & Limpieza & Limpieza & 0 & 3 \\
\hline Xuelin & $36 / 39$ & China/España & Univ./Univ. & Administrativa & Administrativa & Paro & 1 & 5 \\
\hline Akane & $30 / 26$ & Japón/España & Univ./F.P. & Bailarina & $\begin{array}{l}\text { 1.-Paro } \\
\text { 2.-Bailarina } \\
\text { 3.-Baja maternal }\end{array}$ & $\begin{array}{l}\text { Trabajador } \\
\text { empresa } \\
\text { electromecánica }\end{array}$ & 1 & 2 \\
\hline
\end{tabular}




\section{REFERENCIAS BIBLIOGRÁFICAS}

Anthias, F. (2000) "Metaphors of home: gendering new migrations to southern Europe". En F. Anthias y G. Lazarids (Eds.) Gender and Migration in Southern Europe. Oxford: Berg, pp. 15-47.

Aure, M. (2013) "Highly skilled dependent migrants entering the labour market: Gender and place in skill transfer". Geoforum, 45: 275-284.

Catarino, C. y Morokvasic, M. (2005) “Femme, genre, migration et mobilités". Revue Européenne des Migrations Internationales, 21(1): 7-27.

Constable, N. (2003) Romance on a Global Stage. Berkeley: University of California Press.

Constable, N. (Ed.) (2005) Cross-Border Marriages. Philadelphia: University of Pennsylvania Press.

Cooke, F. L. (2007) “'Husband's career first': Renegotiating career and family commitment among migrant Chinese academic couples in Britain". Work Employment and Society, 21 (1): 47-65.

Dumont, J-C., Martin, J-P y Spielvogel, G. (2007) Women on the move: The neglected gender dimension of the brain drain. Bonn: The Institute for the Study of Labor.

Díaz Gil, Ana (2012) La emigración de profesionales cualificados: una reflexión sobre las oportunidades para el desarrollo. Madrid: Organización Internacional para las Migraciones, Secretaría General de Inmigración y Emigración.

Ehrenreich, B. y Hochschild, A. R. (2003) Global Woman. London: Granta Books.

Fox, R. (1967) Kinship and Marriage. Harmondsworth: Penguin.

Glodava, M. y Onizuka, R. (1994) Mail-Order Brides: Women For Sale. Fort Collins, Colo: Alaken.

Halualani, R. (1995) "The Intersecting Hegemonic Discourses of an Asian MailOrder Bride Catalog: Pilipina 'Oriental Butterfly' Dolls for Sale'. Women's Studies in Communication 118 (1): 45-64.

Harris, J.R. y Todaro, M.P. (1970) "Migration, unemployment and development: a two sector analysis". Economic Review 60: 126-142.

Harzig, C. J, (2001) "Women Migrants as Global and local Agents: New Research Strategies on Gender and Migration". En: P. Sharpe (Ed.) Women, Gender and Labor Migratio-Historical and Global Perspectives. London: Routledge, pp. 15-28.

Ho, C. y Alcorso, C. (2004) "Migrants and employment: Challenging the success story". Journal of Sociology 40 (3): 237-259. 
Hondagneu-Sotelo, P. (2001) Domestica: immigrant workers cleaning and caring in the shadows of affluence. Berkeley: University of California Press.

Illouz, E. (2012) Por qué duele el amor. Madrid: Katz.

Joshi, M. S. y Krishna, M. (1998) "English and North American Daughters-in-Law in the Hindu Joint Family”. En: R. Breger y R. Hill (Eds.) Cross-Cultural Marriage. Oxford: Berg, pp. 171-191

King, R. (2002) “Towards a New Map of European Migration”. International Journal of Population Geography 8: 89-106.

Knörr, J. y Meier, B. (2000) Women and Migration. New York: St. Martin’s Press.

Kofman, E. (2000) "The invisibility of skilled female migrants and gender relations in studies of skilled migration in Europe". International Journal of Population Geography 6: 45-59.

Koser, K. y Salt, J. (1997) "The geography of highly skilled international migration". International Journal of Population Geography 3 (4): 285-303.

Larsen, W. (1998) Confessions of a Mail Order Bride: American Life through Thai Eyes. Far Hills: New Horizon Press.

Lee, M. y Piper, N. (2003) "Reflections on transnational life-course and migratory patterns of middle-class women. Preliminary observations from Malaysia". En: N. Piper y M. Roces (Ed.) Wife or worker? Asian women and migration. New York: Rowan \& Littlefield Publishers, Inc., pp. 121-136.

Lévi-Strauss, C. (1981) Las estructuras elementales del parentesco. Barcelona: Paidós.

Mainardi, G. (2006) Miroirs migratoires. Entre le Brésil et la Suisse: vécus de femmes brésiliennes. Bern: Peter Lang.

Man, G. (2004) "Gender, work and migration: deskilling Chinese immigrant women in Canada”. Women's Studies International Forum 27: 135-148.

Massey, D. (1994) Space, Place and Gender. Minneapolis: University of Minnesota Press.

McKay, D. (2003) "Filipinas in Canada - De-skilling as a push toward marriage". En: N. Piper y M. Roces (Ed.) Wife or worker? Asian women and migration. New York: Rowan \& Littlefield Publishers, Inc., pp. 23-52.

Meares, C. (2010) “A fine balance: Women, work and skilled migration”. Women's Studies International Forum 33: 473-481.

Morokvasic, M. (1984) "Birds of passage are also women". International Migration Review 18 (4): 886-907. 
Ordóñez, R. (1997) “Mail-Order Brides: An Emerging Community”. En M. P. Root (Ed.) Filipino Americans: Transformation and Identity. Thousand Oaks: Sage Publications, pp. 121-142.

Parreñas, R. S. (2001) Servants of globalization: women, migration and domestic work. Stanford, CA: Stanford University Press.

Penny, J. y Khoo, S.E. (1996) Intermarriage. A Study of migration and integration. Canberra: Australian Government Publishing Service.

Phizacklea, A. (1983) "Migration and globalization: a feminist perspective”. En: K. Koser y H. Lutz (Eds.) The New Migration in Europe: Social Constructions and Social Realities. Basingstoke: Macmillan, pp. 21-38.

Piper, N. y Roces, M. (Ed.) (2003) Wife or worker? Asian women and migration. New York: Rowan \& Littlefield Publishers, Inc.

Purkayastha, B. (2005) "Skilled migration and cumulative disadvantage: the case of highly qualified Asian Indian immigrant women in the US”. Geoforum 36: 181-196.

Riaño, Y. y Baghdadi, N. (2007) "Understanding the labour market participation of skilled immigrant women in Switzerland: The interplay of class, ethnicity, and gender". Int. Migration \& Integration 8:163-183.

Riaño, Y.; Limacher, K.; Aschwanden, A.; Hirsig, S.; Wastl-Walter, D. (2015) "Shaping gender inequalities: critical moments and critical places". Equality, Diversity and Inclusion: An International Journal, 34(2): 155-167.

Robinson, K. (1996) “Of Mail-Order Brides and 'Boys Own' Tales: Representations of Asian-Australian Marriages”. Feminist Review, 52: 53-68.

Roca, J. (2007) “Migrantes por amor. La búsqueda y formación de parejas transnacionales". AIBR 2: 430 - 458 .

Roca, J. (2011) "[Re]buscando el amor: Motivos y razones de las uniones mixtas de hombres españoles con mujeres extranjeras". Revista de Dialectología y Tradiciones Populares, 66(2): 487-514.

Roca, J.; Anzil, V. y Martínez, L. (2015) "Intimacies turned on and off: Spanish men on search of a foreign partner beyond the screen.” En: B. Enguix y J. Roca (Eds.). Rethinking romantic love. Newcastle: Cambridge Scholars Publishing, pp. 61-100.

Roer-Strier, D. y Ezra, D. (2006) “Intermarriages between Western Women and Palestinian Men: Multidirectional Adaptation Processes". Journal of Marriage and Family. 68, 1: 4155.

Rothenberg, J. (1977) International Migration: A comparative perspective. Nueva York: Academia Press. 
Scholes, R. (1999) “The Mail Order bride industry and its impact on immigration". International Matchmaking Organizations: A Report to Congress (Appendix A). [Recuperado el 4 de abril de 2015] . http://www.ins.usdoj.gov/graphics/aboutins/ repsstudies.Mobrept full.pdf.

Simons, L. A. (1999) "Mail-order brides: The legal framework and possibilities for change". En: G. A. Kelson y D. DeLaet (Eds.) Gender and Immigration, New York: N. Y. University Press, pp. 127-143.

Sinke, S.M. (1999) "Migration for labor, migration for love: marriage and family formation across borders". Magazine of History. Organization of American Historians (Fall 1999: 17-21).

Yeoh, B. y Willis, K. (2005) "Singaporeans in China: Transnational women elites and the negotiation of gendered identities". Geofurum 36: 211-222.

Zolberg, A. R. (1983) “The Next Waves: Migration Theory for a Changing World”. En: R. Cohen Theories of Migration. Cheltenham: Edward Elgar Publishing. 